\title{
sciendo
}

\section{MYOSIN HEAVY CHAIN COMPOSITION, RATE OF DYSTROPHIN AND INTEGRIN DEGRADATION AND MEAT QUALITY OF PIG LONGISSIMUS THORACIS AND PSOAS MAJOR MUSCLES DURING POSTMORTEM AGING*}

\author{
Dorota Wojtysiak \\ Department of Animal Genetics, Breeding and Ethology, University of Agriculture in Krakow, \\ Al. Mickiewicza 24/28, 30-059 Kraków, Poland \\ Corresponding author: wojtysiakd@wp.pl
}

\begin{abstract}
This study evaluated myosin heavy chain composition and the effect of aging time (45 min, $24 \mathrm{~h}$, $96 \mathrm{~h}$ and $168 \mathrm{~h}$ ) on meat quality parameters and dystrophin and integrin degradation pattern in longissimus thoracis and psoas major muscles of 24 Polish Landrace fatteners slaughtered at 100 $\mathrm{kg}$ body weight. It was found that $\boldsymbol{m}$. longissimus thoracis had a greater percentage of MyHC-IIB $(\mathrm{P} \leq \mathbf{0 . 0 5})$ and a significantly lower percentage of type I and IIA/IIX $(\mathrm{P} \leq 0.05)$ compared with the $m$. psoas major. Moreover, psoas major muscle had significantly higher $(\mathrm{P} \leq 0.05) \mathbf{p H}_{45}, \mathbf{p H}_{24}$ and lower drip loss values for $45 \mathrm{~min}$ to $24 \mathrm{~h}, 45 \mathrm{~min}$ to $96 \mathrm{~h}$ and $45 \mathrm{~min}$ to $168 \mathrm{~h}$ than $\mathrm{m}$. longissimus thoracis. Muscle type also had a significant effect on the rate of dystrophin and integrin degradation postmortem, which were significantly $(\mathrm{P} \leq \mathbf{0 . 0 5})$ more rapidly degraded in the $\boldsymbol{m}$. longissimus thoracis compared to the $m$. psoas major. It is concluded from the obtained results that the muscles with a greater percentage of MyHC-IIB show lower $\mathrm{pH}$ values, which translates into more rapid rate of integrin and dystrophin degradation. Ultimately, this may contribute to higher drip loss values during refrigerated storage.
\end{abstract}

Key words: cold storage, myosin heavy chain isoforms, protein degradation, meat quality, pig

Meatiness and pig meat quality are influenced by numerous environmental and genetic factors, and by their interaction. An important contribution to the physicochemical parameters of meat is also made by the microstructure of muscle fibres, including particularly their composition (Ryu and Kim, 2005; Lefaucheur, 2010; Lee et al., 2012; Wojtysiak, 2014). Fibres of mammalian skeletal muscle have been classified on the basis of various physiological, morphological and biochemical

*This study was supported by NCRD, project "ENERGYFEED”, BIOSTRATEG/297910/ NCBR/2016. 
parameters and attempts have been made to make functional correlations. Peter et al. (1972) correlated aerobic-oxidative and glycolytic capacities of muscle fibres to physiological measurements and myosin ATPase activity to give rise to the classification system, slow-twitch oxidative (SO), fast-twitch oxidative-glycolytic (FOG), and fast-twitch glycolytic (FG). Using histochemical methods these fibre types are designated as types I, IIA and IIB by Brooke and Kaiser (1970), types $\beta \mathrm{R}$ (red), $\alpha \mathrm{R}$ and $\alpha \mathrm{W}$ (white) by Ashmore et al. (1972), respectively. Fibre types are also often defined by the isoforms of myosin heavy chain (MyHC) that are present. MyHCs are the motor proteins of muscle thick filaments that, along with actin filaments are able to convert chemical energy to mechanical energy for muscle contraction. Most organisms produce many muscle $\mathrm{MyHC}$ isoforms with temporally and spatially regulated expression patterns. This suggests that isoforms of $\mathrm{MyHC}$ have different characteristics necessary for defining specific muscle properties. Adult pig muscles express four major MyHC isoforms namely: MyHC-I, MyHC-IIA, MyHC-IIX and MHC-IIB. Muscle fibre composition, and thus myosin isoform composition are dependent on both genetic and environmental factors (Pette and Staron, 2000; Greaser et al., 2001; Lefaucheur et al., 2004; Ruusunen and Puolanne, 2004; Wojtysiak and Połtowicz, 2014; Kim et al., 2017). A major role is also played by the function and anatomical location of a muscle (Essen-Gustavsson, 1993). Therefore, by influencing muscle fibre parameters, it is possible to modulate not only muscle physiological parameters, but also physicochemical parameters of pig meat (Oksbjerg et al., 2000). What is more, muscle histochemical profile is an important determinant of the biochemical processes in the muscle, which has a significant effect on the conversion of muscle to meat (Klont et al., 1998; Wojtysiak and Połtowicz, 2015). Differences in postmortem meat quality are also associated with the rate of cytoskeletal protein degradation, which translates directly into physicochemical parameters of the meat (Klont et al., 1998; Melody et al., 2004; Wojtysiak and Połtowicz, 2015; Carlson et al., 2017; Richardson et al., 2017). Cytoskeletal proteins are a complex network of fibrous structures that account for over $85 \%$ of the cell's proteins. They are the group of dynamic proteins that permits the cells to have the proper shape and to perform any cellular movement, as well as the movement of structures inside the cell. The cytoskeleton is composed of three types of fibres: microtubules, microfilaments, and intermediate filaments. In muscle fibres, the continuous attachment from the cytoskeleton to the extracellular matrix is formed by two specific families of proteins, namely members of the dystrophin/dystroglycan complex (Zubrzycka-Gaarn et al., 1988; Omairi et al., 2019) and the integrins (Hynes, 1992; Campbell and Humphries, 2011). Taylor et al. (1995) suggested that one of the important cytoskeletal proteins is dystrophin, which serves an essential function in the formation of costameres protein assemblies which maintain sarcolemmal stability and selective permeability, while integrins are a family of adhesion receptors that mediate interactions between the extracellular matrix and the cytoskeleton (van der Flier and Sonnenberg, 2001). Integrins are heterodimeric proteins made up of $\alpha$ and $\beta$ chains that form many different combinations. The $\beta$ chains of integrin are predominantly responsible for the attachment of the cell membrane to the cell body. On the other hand, the $\alpha$ chains have been more often implicated in matrix interactions (Cukierman et al., 2002). 
Although several $\alpha$ and $\beta$ chains have been described in muscle fibres, $\beta 1$ subunit is most studied (Lawson, 2004). Recently, several studies have shown that degradation of cytoskeletal and other structural proteins like integrin play an important role in drip loss (Melody et al., 2004; Lawson, 2004; Zhang et al., 2006; 2011; Yin et al., 2014; Wojtysiak and Górska, 2018).

The conversion of muscle to meat is controlled by intracellular enzymes, mainly calpains which are in direct contact with myofibrils in the muscle fibre and are able to degrade proteins. Cytoskeletal proteins of the muscle fibres are the main substrates of proteolytic systems, and their degradation makes muscle fibre structure less dense and causes the meat to tenderize (Nowak, 2005; Ouali et al., 2006). Melody et al. (2004) and Zhang et al. (2006) suggested that the degradation of cytoskeletal proteins and protein oxidation can be involved in the regulation of drip loss during postmortem aging. Therefore, essential to understanding changes in the physicochemical parameters during the conversion of muscle to meat is to identify both the muscle microstructure and the rate of cytoskeletal protein degradation.

Therefore, the aim of this study was to determine the myosin heavy chain composition and changes postmortem in dystrophin and integrin degradation and physicochemical properties of $m$. longissimus thoracis and $m$. psoas major in fattening pigs.

\section{Material and methods}

\section{Sample collection}

A total of 24 Polish Landrace fatteners were investigated. Animals were housed in the same environmental condition and production regime of the Pig Performance Testing Station at the Experimental Station of the National Research Institute of Animal Production in Chorzelów (latitude 50¹7'13'N , longitude 21²5'26'E). Pigs were purchased for the Station at about 24-26 kg of body weight and placed into individual pens enabling free movement $(1.6 \mathrm{~m}$ wide $\times 3 \mathrm{~m}$ long). The control fattening at $30 \mathrm{~kg}$ of body weight was started by weighing animals at 7-day intervals to calculate daily gain. The two phase fattening lasted until pigs had attained $100 \mathrm{~kg}$ $( \pm 3 \mathrm{~kg}$ ) of body weight. Animals were fed ad libitum complete feed rations containing 13.1 and 13.0 MJ ME (megajoules of metabolizable energy) and 176 and $145 \mathrm{~g}$ of crude protein per $\mathrm{kg}$ of grower and finisher diet, respectively, according to DLG standards (DLG, 2011). Pigs were slaughtered in a commercial slaughterhouse. Feed was withdrawn $12 \mathrm{~h}$ before slaughter but water was freely available in lairage. The pigs were stunned with $\mathrm{CO}_{2}$ and processed according to the normal slaughterhouse procedures (exsanguinated, scalded, dehaired and eviscerated).

\section{Meat quality analysis}

To determine dystrophin and integrin degradation pattern and meat quality traits, samples of $m$. longissimus thoracis and $m$. psoas major were collected immediately after slaughter, and divided so that all tests could be carried out on the slaughter day (45 min postmortem) and repeated at $24 \mathrm{~h}, 96 \mathrm{~h}$ and $168 \mathrm{~h}$ postmortem. From each 
muscle, four large samples (about $250 \mathrm{~g}$ each) and two small samples (about $50 \mathrm{~g}$ each - to determine drip loss) were excised. The first large sample was used to determine $\mathrm{pH}$ of meat, and to determine intact dystrophin and integrin (Western-blot analysis) 45 min postmortem. The other three samples were vacuum packed and cold stored at $4{ }^{\circ} \mathrm{C}$ to perform analogous analyses within the planned time frame of $24 \mathrm{~h}$, $96 \mathrm{~h}$ and $168 \mathrm{~h}$ postmortem. The samples for the determination of drip loss and meat acidity were cold stored in tightly sealed containers until the end of the experiment at $168 \mathrm{~h}$ postmortem.

Additionally, to determine myosin heavy chain (MyHC) composition, from all of the analysed longissimus thoracis and psoas major muscles, tissue samples were collected $45 \mathrm{~min}$ postmortem, frozen in liquid nitrogen, and homogenized. Whole muscle extracts were obtained by homogenizing one gram of frozen muscle samples with 10 volumes of extraction buffer (50mM Tris- $\mathrm{HCl}, \mathrm{pH} 8.3$, and 10mM EDTA) using a Polytron (Wheeler and Koohmaraie, 1999). The muscle homogenate was diluted $1: 1$ and mixed with protein denaturing buffer $(4 \%$ [wt/vol] SDS, $20 \%$ [vol/vol] glycerol, and $125 \mathrm{mM}$ Tris- $\mathrm{HCl}, \mathrm{pH} 6.8$ ) and heated at $50^{\circ} \mathrm{C}$ for $20 \mathrm{~min}$. Samples were centrifuged at $14,000 \times \mathrm{g}$ for $20 \mathrm{~min}$. Next, samples were diluted to $2 \mathrm{mg} / \mathrm{ml}$ and mixed with protein denaturing buffer (125 mM Tris HCL, pH 6.8, 4\% [wt/vol] SDS, $20 \%$ [vol/vol] glycerol, $0.2 \%$ [vol/vol] $\beta$-mercaptoethanol [MCE], and $0.013 \%$ [vol/ vol] Coomassie Brilliant Blue G-250) and heated at $50^{\circ} \mathrm{C}$ for $20 \mathrm{~min}$. The protein concentration was determined using Bicinchoninic Acid Protein Assay Kit (BCA) (Sigma Chemical Co, St. Louis, USA). All extraction and centrifugation took place at $4^{\circ} \mathrm{C}$. Myosin heavy chain (MyHC) isoforms were determined using a procedure described by Talmadge and Roy (1993) with modifications as previously reported by Wojtysiak and Połtowicz (2014). Briefly, an 8\% separating acrylamide gel (acrylamide: N,N'-bis-methylene acrylamide $=100: 1[\mathrm{wt} / \mathrm{wt}$ ], 0.4\% [wt $/ \mathrm{vol}] \mathrm{SDS}, 0.05 \%$ [vol/vol] TEMED, $0.1 \%$ [wt/vol] APS, 30\% [vol/vol] glycerol, 200mM Tris-HCl, pH 8.8 , and $100 \mathrm{mM}$ glycine) and a $4 \%$ stacking acrylamide gel (acrylamide: N,N'-bismethylene acrylamide $=50: 1$ [wt $/ \mathrm{wt}], 0.4 \%$ [wt $/ \mathrm{vol}] \mathrm{SDS}, 0.05 \%$ [vol $/ \mathrm{vol}] \mathrm{TEMED}$, $0.1 \%$ [wt/vol] APS, 30\% [vol/vol] glycerol, $4 \mathrm{mM}$ EDTA, and $70 \mathrm{mM}$ Tris- $\mathrm{HCl}$, $\mathrm{pH}$ 6.7) were used for determination of MyHC isoforms. Gels $(8 \mathrm{~cm}$ wide $\times 6 \mathrm{~cm}$ high) for MyHC were run on a Mini-PROTEAN® II electrophoresis system (Bio$\mathrm{Rad}, \mathrm{USA})$. The running buffer for the upper chamber contained $300 \mathrm{mM}$ Tris- $\mathrm{HCl}$, $450 \mathrm{mM}$ glycine, $0.3 \%$ [wt/vol] SDS, and $0.2 \%$ [vol/vol] MCE and the running buffer for the lower chamber contained $50 \mathrm{mM}$ Tris- $\mathrm{HCl}, 75 \mathrm{mM}$ glycine, and $0.05 \%$ [wt/wt] SDS. Gels for MyHC were loaded with $1 \mu \mathrm{g}$ of protein per lane. Relative molecular weights were determined using PageRulerTM Plus Prestained Protein Ladder. Electrophoresis was performed at constant voltage of $100 \mathrm{~V}$ for $18 \mathrm{~h}$ at $4^{\circ} \mathrm{C}$. The bands were visualized by $0.2 \%$ [wt/vol] Coomassie Brilliant Blue R-250, 40\% [vol/vol] methanol, and 10\% [vol/vol] glacial acetic acid. Gels were destained using an excess of $40 \%$ [vol/vol] methanol and $7 \%$ [vol/vol] glacial acetic acid. Analysis was made of the MyHC isoform types I, IIA, IIB and IIX. However, because types IIA and IIX were not separated in the analysis due to the difficulty in differentiating between the two bands using densitometry, percentages of type I, type IIA and IIX (together), and type IIB were analysed in each muscle. The density of type I, 
IIA/IIX and IIB MyHC bands was quantified by the densitometric method (ImageJ ver. 1.33U, National Institutes of Health, USA). Within each sample, percentages for each $\mathrm{MyHC}$ isoform were calculated as a percentage of the total MyHC isoforms in each lane.

Muscle pH was measured using a Matthäus (Germany) $\mathrm{pH}$ meter with a glass electrode standardized for $\mathrm{pH} 4.0$ and 7.0 according to Polish Standard PN-77/a-82058 with automatic correction for muscle temperature at $45 \mathrm{~min}, 24 \mathrm{~h}$, $96 \mathrm{~h}$, and $168 \mathrm{~h}$ postmortem. Drip loss was measured in duplicate samples. After thorough weighing $(\mathrm{e}=0.001 \mathrm{~g})$, samples were placed in sealed containers. After $24 \mathrm{~h}$ of storage samples were removed from their individual sealed containers, towel dried, and weighed again. The chops were then placed in new sealed containers and stored for an additional hour. Following $96 \mathrm{~h}$ of storage samples were again towel dried and weighed. Similarly, the samples of meat were processed after $168 \mathrm{~h}$ of storage. Drip loss results were presented as cumulative values for $45 \mathrm{~min}$ to $24 \mathrm{~h}, 45 \mathrm{~min}$ to $96 \mathrm{~h}$ and $45 \mathrm{~min}$ to $168 \mathrm{~h}$.

Intact dystrophin and integrin were analysed using Western immunoblotting according to Wojtysiak and Górska (2018). To this end, whole muscle extracts were obtained by homogenizing muscle samples with 10 volumes of ice cold extraction buffer ( $\mathrm{pH} 8.3$ ) containing $50 \mathrm{mM}$ Tris and $10 \mathrm{mM}$ EDTA. The muscle homogenate was diluted 1:1 with protein denaturing buffer (4\% SDS, 20\% glycerol, $125 \mathrm{mM}$ Tris, $\mathrm{pH}$ 6.8) and heated at $50^{\circ} \mathrm{C}$ for $20 \mathrm{~min}$. Samples were centrifuged at $16000 \times \mathrm{g}$ and protein concentration was determined using BCA assay (Sigma Chemical Co, St. Louis, USA). Dystrophin and integrin were separated by SDS-PAGE on 8\% and $10 \%$ separating acrylamide gel, respectively and with $4 \%$ stacking acrylamide gel. Gels for dystrophin and integrin were loaded with $60 \mu \mathrm{g}$ of protein per lane. Relative molecular weights were determined using PageRulerTM Plus Prestained Protein Ladder (Thermo Fisher Scientific, Inc. Waltham, MA, USA). Discontinuous gels were run at $100 \mathrm{~V}$ for $1.5 \mathrm{~h}$. Gel was transferred to Immobilon-P transfer membrane (Millipore) overnight at $4^{\circ} \mathrm{C}$ and $30 \mathrm{~mA}$ in buffer containing $25 \mathrm{mM}$ Tris, $193 \mathrm{mM}$ glycine, and 15\% methanol. After blocking with 10\% non-fat dried milk in Tris-buffered saline $\mathrm{pH} 7.4$ containing $0.05 \%$ Tween 20 for $1 \mathrm{~h}$, the membrane was incubated at room temperature with primary monoclonal antibody NCLDYS3 (Novocastra, Leica, dilution 1:20) and MAB1900 (Chemicon International, Temecula, CA, dilution 1:1000) for $2 \mathrm{~h}$ at room temperature. Membrane was washed three times ( 5 min) with TBST after each incubation. Bound primary antibody was visualized with goat anti-mouse alkaline phosphatase conjugate (Pierce Chemical Co., USA) diluted 1:2500, followed by detection of alkaline phosphate activity with bromo-chloroindolyl phosphate and nitroblue tetrazolium. The immunoblots were electronically scanned and the intensity of intact dystrophin and intact integrin were calculated using densitometric method (ImageJ ver. 1.33U, National Institutes of Health, USA). Because the same amount of protein from each sample was loaded on SDS gels, relative abundance of intact dystrophin and intact integrin at $45 \mathrm{~min}$ postmortem (as a reference standard to normalize the band intensities) of the $m$. longissimus thoracis and $m$. psoas major samples was taken as $100 \%$ with respect to each muscle sample. The intact dystrophin and integrin contents at $24 \mathrm{~h}$ and $96 \mathrm{~h}$ 
postmortem were expressed as percentages of the 45 min postmortem samples. The obtained ratio was used for statistical analysis.

\section{Statistical analysis}

Differences among the muscle types and time of storage were analysed using analysis of variance (General Linear Models procedure), and tested for differences by Tukey's test. A probability of $\mathrm{P} \leq 0.05$ was considered statistically significant. The data were expressed as least squares means (LSM) \pm standard error (SE).

\section{Results}

The least squares means and standard errors for the percentage of MyHC isoforms and physicochemical parameters ( $\mathrm{pH}$ and drip loss) of $m$. longissimus thoracis and $m$. psoas major are presented in Table 1 . The separation of different types of $\mathrm{MyHC}$ isoforms on polyacrylamide gel is presented in Figure 1.

Table 1. The least squares means (LSM) and standard errors (SE) for the percentage of MyHC isoforms and physicochemical parameters ( $\mathrm{pH}$, drip loss) of $m$. psoas major (PM) and $m$. longissimus thoracis (LTh) from Polish Landrace fatteners

\begin{tabular}{|c|c|c|}
\hline Item & PM & LTh \\
\hline \multicolumn{3}{|c|}{ Percentage of MyHC isoforms (\%) } \\
\hline MyHC-I & $20.6 \mathrm{a} \pm 0.19$ & $10.3 \mathrm{~b} \pm 0.31$ \\
\hline MyHC-IIA/IIX & $33.8 \mathrm{a} \pm 0.34$ & $21.5 \mathrm{~b} \pm 0.26$ \\
\hline MyHC-IIB & $45.6 \mathrm{a} \pm 0.62$ & $68.2 \mathrm{~b} \pm 0.46$ \\
\hline \multicolumn{3}{|c|}{ pH } \\
\hline $45 \min$ & $6.45 \mathrm{ax} \pm 0.02$ & $6.28 \mathrm{bx} \pm 0.03$ \\
\hline $24 \mathrm{~h}$ & 5.94 ay \pm 0.04 & 5.69 by \pm 0.02 \\
\hline $96 \mathrm{~h}$ & 5.74 ay \pm 0.05 & 5.66 ay \pm 0.04 \\
\hline $168 \mathrm{~h}$ & 5.75 ay \pm 0.06 & $5.67 \mathrm{ay} \pm 0.04$ \\
\hline \multicolumn{3}{|c|}{ Drip loss } \\
\hline $45 \mathrm{~min}-24 \mathrm{~h}$ & $0.59 \mathrm{ax} \pm 0.09$ & $1.91 \mathrm{bx} \pm 0.12$ \\
\hline $45 \min -96 h$ & $1.86 \mathrm{ay} \pm 0.06$ & 4.05 by \pm 0.18 \\
\hline $45 \mathrm{~min}-168 \mathrm{~h}$ & $2.74 \mathrm{az} \pm 0.08$ & $5.89 \mathrm{bz} \pm 0.11$ \\
\hline
\end{tabular}

$\mathrm{a}, \mathrm{b}$ - values in rows with different letters are significantly different $(\mathrm{P} \leq 0.05)$.

$\mathrm{x}, \mathrm{y}, \mathrm{z}-$ values in columns with different letters are significantly different $(\mathrm{P} \leq 0.05)$.

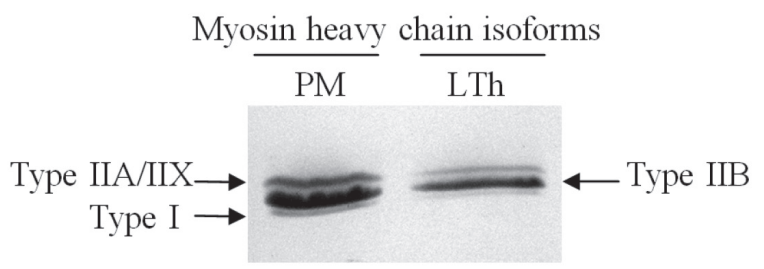

Figure 1. Electrophoretic separation of MyHC isoforms $(220 \mathrm{kDa})$ in $m$. psoas major $(\mathrm{PM})$ and $m$. longissimus thoracis (LTh) obtained from Polish Landrace fatteners. The top band is the type IIA/IIX isoforms, the second band is the type IIB isoforms, and the bottom band is the type I MyHC isoforms 
In turn, $m$. longissimus thoracis had a greater percentage of MyHC-IIB and significantly lower percentage of type I and IIA/IIX compared with the $m$. psoas major.

The analysis of physicochemical parameters in both muscles showed a significant $(\mathrm{P} \leq 0.05)$ decrease in $\mathrm{pH}$ value at $24 \mathrm{~h}$ compared to 45 min postmortem. Further refrigerated storage of the meat did not have a significant $(\mathrm{P} \geq 0.05)$ effect on the values of this parameter in relation to $24 \mathrm{~h}$ postmortem for both the $m$. longissimus thoracis and the $m$. psoas major. Statistically significant $(\mathrm{P} \leq 0.05)$ differences were observed, however, when comparing the acidity of the analysed muscles in different storage periods. Accordingly, the $m$. longissimus thoracis showed significantly $(\mathrm{P} \leq 0.05)$ lower $\mathrm{pH}$ values at $45 \mathrm{~min}$ and $24 \mathrm{~h}$ postmortem in relation to the $m$. psoas major. The time of refrigerated meat storage also had a significant $(\mathrm{P} \leq 0.05)$ effect on the drip loss value. With prolonged refrigerated storage, the total value of this parameter was observed to increase $(\mathrm{P} \leq 0.05)$ in both the $m$. longissimus thoracis and $m$. psoas major. In terms of the muscle type, drip loss at $24 \mathrm{~h}, 96 \mathrm{~h}$ and $168 \mathrm{~h}$ postmortem was significantly $(\mathrm{P} \leq 0.05)$ higher in the $m$. longissimus thoracis compared to the m. psoas major.

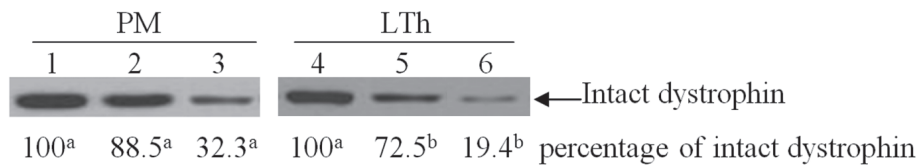

Figure 2. Western blot analysis of dystrophin (427 kDa) in m. psoas major (PM) and m. longissimus thoracis (LTh) obtained from Polish Landrace fatteners. Samples were stored for 45 min (lines 1, 4), $24 \mathrm{~h}$ (lines 2, 5), and $96 \mathrm{~h}$ (lines 3, 6). Least squares means (LSM) (between PM and LTh muscles) with different subscript are significantly different: $a, b(P \leq 0.05)$

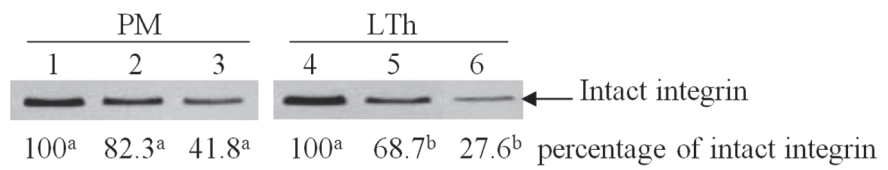

Figure 3. Western blot analysis of integrin $(130 \mathrm{kDa})$ in $m$. psoas major $(\mathrm{PM})$ and $m$. longissimus thoracis (LTh) obtained from Polish Landrace fatteners. Samples were stored for 45 min (lines 1, 4), $24 \mathrm{~h}$ (lines 2, 5), and $96 \mathrm{~h}$ (lines 3, 6). Least squares means (LSM) (between PM and LTh muscles) with different subscript are significantly different: $a, b(P<0.05)$

The results of dystrophin and integrin degradation in pig $m$. longissimus thoracis and $m$. psoas major during postmortem storage are presented in Figures 2 and 3 . The Western-blot analysis showed that dystrophin degradation during $96 \mathrm{~h}$ refrigerated storage of the meat did not occur evenly in both analysed muscles. Accordingly, both $24 \mathrm{~h}$ and $96 \mathrm{~h}$ postmortem the degree of intact dystrophin in $m$. psoas major was significantly $(\mathrm{P} \leq 0.05)$ greater than in $m$. longissimus thoracis. Similar to dystrophin, more intact integrin $(\mathrm{P} \leq 0.05)$ was shown in $m$. psoas major after 24 and 96 h postmortem compared to $m$. longissimus thoracis. 


\section{Discussion}

Culinary quality of meat is largely determined by postmortem changes which occur in muscle tissue (Carlson et al., 2017; Richardson et al., 2017). These include acidity, drip loss, and degradation of cytoskeletal proteins. Another important determinant of the value of slaughter products is their microstructure as well as histochemical profile of the muscles, which is influenced, among others, by the content of different myosin isoforms.

The Western-blot analysis performed in our study demonstrated that myosin heavy chain composition of $m$. longissimus thoracis is dominated by MyHC-IIB. Such a large proportion of MyHC-IIB in the m. longissimus thoracis, due to its specific characteristics, makes it glycolytic. These conjectures are supported by earlier studies by Ruusunen and Puolanne (2004) and Lefaucheur et al. (2004), which showed that pig $m$. longissimus is a typical "white" muscle with glycolytic metabolism. Also in the case of m. psoas major, our study showed that MyHC-IIB forms the highest percentage in myosin heavy chain composition. However, it is worth noting that in the $m$. longissimus thoracis, MyHC-IIB percentage is considerably higher and percentages of MyHC-I and IIA/IIX, which is indicative of oxidative metabolism, are considerably lower than in $m$. psoas major. These results confirm the earlier observations of Kim et al. (2017). As indicated by Essen-Gustavsson (1993), such variation in the muscle fibre composition and the resulting differences in the composition of individual MyHC isoforms between different pig muscles, are mainly due to the anatomical location of the muscles and the functions they serve. Earlier study showed that the contractile function of skeletal muscles is primarily regulated by the expression of MyHC isoforms (Potau et al., 2012). Therefore, the muscles with higher MyHC-I content are slow but resistant to fatigue, while those with major expression of MyHC-IIA and MHC-IIB are fast and powerful but less resistant to fatigue.

The results of qualitative analysis obtained in our study show a significant effect of the muscle type on the physicochemical parameters. Accordingly, the higher $\mathrm{pH}$ values noted in $m$. psoas major compared to $m$. longissimus thoracis at $45 \mathrm{~min}$ and $24 \mathrm{~h}$ postmortem may result, among others, from the differences in myosin heavy chain composition. Fernandez et al. (1995) and Kwasiborski et al. (2008) assert that glycolytic muscles, which have a higher percentage of MyHC-IIB and type IIB muscle fibres, are characterized by lower $\mathrm{pH}_{45}$ and $\mathrm{pH}_{24}$ values, unlike type I oxidative muscles (with a high MyHC-I content), which show higher $\mathrm{pH}$. These suppositions agree with an earlier study by Choe et al. (2008). Similarly, Kang et al. (2011) demonstrated that the content of MyHC slow isoform (I), unlike MyHC fast isoform (IIB), was positively correlated with muscle $\mathrm{pH}_{24}$. In turn, the $\mathrm{pH}$ decline $24 \mathrm{~h}$ postmortem, shown in our study in both analysed muscles, results according to Karlsson et al. (1999) from the rate of ATP hydrolysis, and thus it depends on ATPase activity. Bee et al. (2007) and Huff-Lonergan and Lonergan (2005) suggest that the decline in muscle $\mathrm{pH}$ during the early postmortem storage period may influence the intermediate filaments of muscle fibres and costameres, which may cause the muscle fibres to contract. 
The postmortem changes which occur in meat during storage, determine another quality parameter, namely drip loss. It is obvious that cumulative drip loss increases with increasing period of meat storage (Zhang et al., 2006; Bee et al., 2007). Accordingly, as could be expected, in both analysed muscles, total drip loss increased with prolonged refrigerated storage of the meat. These results confirm the earlier observations of Kristensen and Purslow (2001) and Wojtysiak and Połtowicz (2015). Ryu and Kim (2005) demonstrated that increased drip loss is closely associated with a high percentage of type IIB fibres. For type I muscle fibres, the authors observed negative correlations. Therefore, the higher drip loss observed in our study in the $m$. longissimus thoracis compared to the $m$. psoas major during all the periods of refrigerated meat storage may result from the higher percentage of MyHC-IIB and lower percentage of MyHC-I, which occur in type IIB and I fibres, respectively. These conjectures are supported by Kang et al. (2011), who noted that the content of MyHC-IIB, unlike MyHC-I, was positively correlated with drip loss. It may be also noted that the level of drip loss is significantly influenced by the degradation rate of cytoskeletal proteins, in particular the costameric proteins (Melody et al., 2004; Wojtysiak and Górska, 2018) - and the dystrophin discussed in our study is exactly such a protein. In skeletal muscle fibres, by binding to the glycoprotein complex, dystrophin forms a major structural component of muscle fibres, responsible among others for the coupling of sarcolemma with actin filaments. In turn, by making specific links between the sarcoplasmic cytoskeleton and extracellular matrix, it helps to maintain cell homeostasis (Minetti et al., 1992; Omairi et al., 2019). It is exactly the rate of costamere protein degradation as well as the degradation rate of integrin membrane proteins that largely determine the opening of drip channels, which contribute to the level of drip loss (Kristensen and Purslow, 2001). Lawson (2004) showed integrin to be the principal protein that determines the opening of drip channels. The same author showed that the degradation of the $\beta 1$-chain of integrin, the portion of the protein involved in adhesion of the cell membrane to the cytoskeleton, temporally correlates to the opening of drip channels in pork. It should also be remembered that the rate of cytoskeletal protein degradation is determined by the calpain system, namely proteolytic enzymes such as $\mu$-calpain, m-calpain and their specific inhibitor calpastatin (Nowak, 2005; de Oliveira et al., 2019). Earlier study of Pfaff et al. (1999) showed that the $\beta$-integrin subunit can be readily degraded by calpains in vitro. Hence Lawson (2004) advanced a hypothesis that the degradation of the $\beta 1$ chain of integrin may be due to activation of calpains at the site of adhesion plaques. Moreover, the same author showed that $\mathrm{m}$-calpain is co-localized with $\beta 1$-integrin at the cytoplasmic surface of the cell membrane in plaque-like structures and is active in these regions postmortem. Inhibition of calpains not only results in inhibition of integrin degradation, but blocks the opening of drip channels. Therefore, the opening of drip channels in pork may well be due to the degradation of integrin proteins on the cell surface by calpains. The relationship between drip loss and integrin degradation was also reported by Zhang et al. (2006), who showed that a greater amount of detectable intact integrin is associated with decreased drip loss during postmortem storage in pork. According to the hypothesis of Huff-Lonergan and Lonergan (2005), if costameric linkages remain intact during the conversion of muscle into 
meat, shrinkage of the myofibrils as the muscle goes into rigor would be transmitted to the entire cell via these proteinaceous linkages and would ultimately reduce volume of the muscle cell itself. Thus, the rigor process could result in mobilization of water not only out of the myofibril, but also out of the extramyofibril spaces as the overall volume of the cell is constricted; this may explain the higher drip loss in $m$. longissimus thoracis in our study, where both integrin and dystrophin were degraded more slowly compared to $m$. psoas major.

Morrison et al. (1998) hold that the rate of cytoskeletal protein degradation is affected by muscle fibre composition. Accordingly, cytoskeletal proteins are degraded more rapidly in glycolytic fibres (IIB) that in oxidative fibres (I). As pointed out before, the rate of cytoskeletal protein degradation is determined by the calpain system. These enzymes do not occur freely in the sarcoplasm and their main location in striated skeletal muscle fibres is the myofibril Z-line. Therefore, after slaughter, by degrading the Z-line calpains cause the fragmentation of myofibrils and thus shape physicochemical parameters of the meat. Sazili et al. (2005) indicate that the content of $\mu$-calpain and $\mathrm{m}$-calpain is correlated with the muscle fibre composition, and thereby with the MyHC composition. Likewise, Wojtysiak and Połtowicz (2015) consider that the rate of cytoskeletal protein degradation depends on muscle fibre composition. The same authors observed that the muscles with a higher percentage of type I fibres are also characterized by lower rate of desmin degradation. Therefore, the slower rate of dystrophin degradation, shown in our study in $m$. psoas major compared to $m$. longissimus thoracis, may be partially attributed to the higher content of type I isoform in myosin heavy chain composition.

In summary, it is concluded that $m$. longissimus thoracis is a typical "white" muscle characterized by a significantly greater percentage of MyHC-IIB isoform, in contrast to $m$. psoas major which were found to contain a significantly greater percentage of MyHC-I and MyHC-IIA/IIX isoforms. Moreover, m. psoas major was characterized by significantly higher $\mathrm{pH}_{45}$ and $\mathrm{pH}_{24}$ values, and lower cumulative drip loss values. Additionally, the obtained results indicate that the muscles with a greater percentage of MyHC-IIB show lower $\mathrm{pH}$ values, which contributes to a more rapid rate of integrin and dystrophin degradation. This may result in higher drip loss values during refrigerated storage of the muscles.

\section{References}

A sh mor e C.R., To m p kin s G., D o e r r L. (1972). Postnatal development of muscle fibre types in domestic animals. J. Anim. Sci., 34: 37-41.

B e e G., Anders on A.L., Lon ergan S.M., Huff-Lonergan E. (2007). Rate and extent of $\mathrm{pH}$ decline affect proteolysis of cytoskeletal proteins and water-holding capacity in pork. Meat Sci., 76: 359-365.

B r o o k e M.H., K a i s e r K. (1970). Muscle fibre type: how many and what kind? Arches Neurol., 23: 369-370.

Ca mpbell I.D., Humphries M.J. (2011). Integrin structure, activation, and interactions. Cold Spring Harb. Perspect. Biol., 3: a004994. 
Carlson K.B., Prusa K.J., Fedler C.A., Steadham E.M., Outhouse A.C., King D.A., Huff-L on ergan E., L o n ergan S.M. (2017). Postmortem protein degradation is a key contributor to fresh pork loin tenderness. J. Anim. Sci., 95: 1574-1586.

Cho e J.H., Cho i Y.M., L e e S.H., Shin H.G., Ry u Y.C., Hong K.C. (2008). The relation between glycogen, lactate content and muscle fibre composition, and their influence on postmortem glycolytic rate and pork quality. Meat Sci., 80: 355-362.

Cukierman E., Pankov R., Yamada K.M. (2002). Cell interactions with three-dimensional matrices. Curr. Opin. Cell Biol., 14: 633-639.

Es s e n-Gust a v s s on B. (1993). Muscle fiber characteristics in pigs and relationships to meat quality parameters - review. Swed. J. Agric. Res., 5: 140-155.

F er n a n d e z X., L e v a s s u r P., E c o l a n P. (1995). Effect of epinephrine administration on glycogen metabolism in red and white muscle of anaesthetized pigs (Sus scrofa domesticus). J. Sci. Food Agr., 68: 231-239.

Gre a s e r M.L., O k o c h i H., S o s n i c k i A.A. (2001). Role of fiber types in meat quality. Congress Proc. 47th ICoMST, Kraków, pp. 34-37.

Huff-L on ergan E., L on ergan S.M. (2005). Mechanisms of water-holding capacity of meat: The role of postmortem biochemical and structural changes. Meat Sci., 71: 194-204.

H y n e s R.O. (1992). Integrins - versatility, modulation, and signalling in cell adhesion. Cell, 69: $11-25$.

K ang Y.K., Ch o i Y.M., L e e S.H., C h o e J.H., H ong K.C., K i m B.C. (2011). Effects of myosin heavy chain isoforms on meat quality, fatty acid composition, and sensory evaluation in Berkshire pigs. Meat Sci., 89: 384-389.

K a r l s s o n A.H., K l o n t R.E., X a vi e r F. (1999). Skeletal muscle fibres as factors for pork quality. Livest. Prod. Sci., 60: 255-269.

K i m G.D., Yang H.S., J e o n g J.Y. (2017). Comparison of myosin heavy chain content determination by label-free quantification between porcine longissimus thoracis, psoas major and semimembranosus muscles. Food Res. Int., 100: 504-513.

K lont R.E., Brocks L., Eikele n b o om G. (1998). Muscle fibre type and meat quality. Meat Sci., 49: 219-229.

Kristens en L., Purs low P.P. (2001). The effect of ageing on the water-holding capacity of pork role of cytoskeletal proteins Meat Sci., 58: 17-23.

Kwasiborski A., Sayd T., Chambon C., S anté-Lhoutellier V., Rocha D., Terlouw C. (2008). Pig Longissimus lumborum proteome: Part II: Relationships between protein content and meat quality. Meat Sci., 80: 982-996.

L a w s o n M.A. (2004). The role of integrin degradation in post-mortem drip loss in pork. Meat Sci., 68: 559-566.

L e e S.H., Cho e J.H., Cho i Y.M., Jung K.C., Rhe e M.S., Hong K.C. (2012). The influence of pork quality traits and muscle fibre characteristics on the eating quality of pork from various breeds. Meat Sci., 90: 284-291.

L e fa u che ur L. (2010). A second look into fibre typing - Relation to meat quality. Meat Sci., 84: 257-270.

Lefaucheur L., Milan D., Ecolan P., Le Callennec C. (2004). Myosin heavy chain composition of different skeletal muscles in Large White and Meishan pigs. J. Anim. Sci., 82: 1931-1941.

Melody J.L., Lonergan S.M., Row e L.J., Huiatt T.W., Mayes M.S., Huff-Lonerg a n E. (2004). Early postmortem biochemical factors influence tenderness and water-holding capacity of three porcine muscles. J. Anim. Sci., 82: 1195-1205.

Minetti C., Beltrame F., Marcenaro G., Bonilla E. (1992). Dystrophin at the plasma membrane of human muscle fibers shows a costameric localization. J. Clin. Neuromuscul. Dis., 2: 99-109.

M or r i s on H.E., M i e l c h e M.M., P u r l s o w P.P. (1998). Immunolocalisation of intermediate filament proteins in porcine meat. Fibre type and muscle-specific variations during conditioning. Meat Sci., 50: 91-104.

N ow a k M. (2005). The role of calpains in the meat tenderization process. Zywn.-Nauk. Technol. Ja., 1: 5-17. 
Oksbjerg N., Petersen J.S., Sorensen I.L., Henckel P.P., Vestergaard M., Ertbjerg P., Moller A.J., B ejerholm C., S to ier S. (2000). Long-term changes in performance and meat quality of Danish Landrance pigs: a study on a current compared with an unimproved genotype. Anim. Sci., 71: 81-92.

de Oliveira L.G., Delgado E.F., Steadham E.M., Huff-Lonergan E., Lonerg a n S.M. (2019). Association of calpain and calpastatin activity to postmortem myofibrillar protein degradation and sarcoplasmic proteome changes in bovine Longissimus lumborum and Triceps brachii. Meat Sci., 155: 50-60.

O ma ir i S., Hau K.L., Collins-Hooper H., S cott C., Va iy a puri S., Torelli S., Montanaro F., Mats a kas A., P a tel K. (2019). Regulation of the dystrophin-associated glycoprotein complex composition by the metabolic properties of muscle fibres. Sci. Rep., 9: 2770; doi: 10.1038/s41598-019-39532-4.

Ouali A., Hernan Herrera-Mendez C., Coulis G., B ecila S., Boudjellal A., A u b r y L., S e n t a n d r e u M.A. (2006). Revisiting the conversion of muscle into meat and the underlying mechanisms. Meat Sci., 74: 44-58.

P e ter J.B., B a rnard R.L., Edgert o n V.R., Gille s p i e C.A., S t e m p e 1 K.E. (1972). Metabolic profiles of three fibre types of skeletal muscle in guinea pigs and rabbits. Biochemistry, 11: 627-633.

P e t t e D., S t a r o n R.S. (2000). Myosin isoforms, muscle fibre types, and transitions. Microsc. Res. Techniq., 50: 500-509.

P fa ff M., D u X.P., G i n s b e rg M.H. (1999). Calpain cleavage of integrin p cytoplasmic domains. FEBS Letters, 460: 17-22.

Potau J.M., Artells R., Muñoz C., Díaz T., Bello-Hellegouarch G., Arias-Martorell J., Pére z - Pérez A., Mon zó M. (2012). Expression of myosin heavy chain isoforms in the human supraspinatus muscle: variations related to age and sex. Cells Tissues Organs, 196: $456-462$.

Ruusu E., B ohrer B.M., Arkfeld E.K., B oler D.D., Dilger A.C. (2017). A comparison of intact and degraded desmin in cooked and uncooked pork longissimus thoracis and their relationship to pork quality. Meat Sci., 129: 93-101.

Ruusunen M., Puolanne E. (2004). Histochemical properties of fibre types in muscles of wild and domestic pigs and the effect of growth rate on muscle fibre properties. Meat Sci., 67: 533-539.

R y u Y., K i m B.C. (2005). The relationship between muscle fiber characteristics, postmortem metabolic rate, and meat quality of pig longissimus dorsi muscle. Meat Sci., 71: 351-357.

S a zili A.Q., P arr T., S ens y P.R., J on es S.W., B ards ley R.G., B u st e ry P.J. (2005). The relationship between slow and fast myosin heavy chain content, calpastatin and meat tenderness in different ovine skeletal muscles. Meat Sci., 69: 17-25.

T a $1 \mathrm{~m}$ a d g e R.J., R o y R.R. (1993). Electrophoretic separation of rat skeletal muscle myosin heavychain isoforms. J. Appl. Physiol., 75: 2237-2340.

Taylor R.G., Ge e s ink G.H., Thomp son V.F., Kooh maraie M., Goll D.E. (1995). Is Z-disk degradation responsible for post-mortem tenderization? J. Anim. Sci., 73: 1351-1367.

van der Flier A., S onnenberg A. (2001). Function and interactions of integrins. Cell and Tissue Res., 305: 285-298.

Wh e eler T.L., K o o h marai e M. (1999). The extent of proteolysis is independent of sarcomere length in lamb longissimus and psoas major. J. Anim. Sci., 77: 2444-2451.

W o j t y s i a k D. (2014). Effect of breed on microstructure and tenderness of porcine semimembranosus muscle. Ann. Anim. Sci., 14: 697-705.

Woj ty s i a k D., Gór s k a M. (2018). Effect of aging time on meat quality and rate of desmin and dystrophin degradation of pale, soft, exudative (PSE) and normal turkey breast muscle. Folia Biol. (Kraków), 66: 63-72.

W oj ty s i a k D., P oł to w i c z K. (2014). Carcass quality, physico-chemical parameters, muscle fibre traits and myosin heavy chain composition of $\mathrm{m}$. longissimus lumborum from Puławska and Polish Large White pigs. Meat Sci., 97: 395-403.

Wojtysiak D., Połtowicz K. (2015). Effect of ageing time on microstructure, rate of desmin degradation and meat quality of pig longissimus lumborum and adductor muscles. Folia Biol. (Krakow), 63: 151-158. 
Y in Y., Zh ang W.G., Z h o u G.H., G u o B. (2014). Comparison of protein degradation, protein oxidation, and $\mu$-calpain activation between pale, soft, and exudative and red, firm, and nonexudative pork during postmortem aging. J. Anim. Sci., 92: 3745-3752.

Zhang W.G., Lonergan S.M., Gardner M.A., Huff-Lonergan E. (2006). Contribution of postmortem changes of integrin, desmin and $\mu$-calpain to variation in water holding capacity of pork. Meat Sci., 74: 578-585.

Zhang W.G., Xi a o S., L e e E.J., A h n D.U. (2011). Consumption of oxidized oil increases oxidative stress in broilers and affects the quality of breast meat. J. Agric. Food Chem., 59: 969-974.

Zubrzycka-Gaarn E.E., Bulman D.E., Karpati G., Burghes A.H.M., B elfall B., Kalmut H.J., Talbot J., Hodges R.S., R a y P.N., Worton R.G. (1988). The Duchenne muscular dystrophy gene product is localised in sarcolemma of human skeletal muscle. Nature, 333: 466-469.

Received: 5 VI 2019

Accepted: 12 IX 2019 